\title{
Support characteristics of eco-spiral pile with respect to twisting angle and ratio of borehole diameter to pile width
}

\author{
Seong-Seung Kanga ${ }^{\mathrm{a}}$, Jeongdu Noh ${ }^{\mathrm{b}}$, Hyongdoo Jang ${ }^{\mathrm{c} 1}$ \\ ${ }^{a}$ Department of Energy \& Resources Engineering, Chosun University, Gwangju, \\ Republic of Korea; ${ }^{\mathrm{b}}$ The Research Institute of Advanced Engineering Technology, \\ Chosun University, Gwangju, Republic of Korea; ${ }^{c}$ Western Australian School of Mines, \\ Curtin University, Kalgoorlie, Australia \\ (Received xxx; accepted xxx)
}

Seong-Seung Kang: Dept. of Energy \& Resources Engineering, Chosun University, Gwangju 61452, Republic of Korea. Office: +82 62230 7112. Fax: +82-96-233-2110. E-mail:

kangss@chosun.ac.kr

Jeongdu Noh: The Research Institute of Advanced Engineering Technology, Gwangju 61452, Republic of Korea. Office: +82 62230 7876. E-mail: wjden1655@ naver.com

Hyongdoo Jang ${ }^{1}$ : Western Australian School of Mines, Curtin University, Australia. Office: +61 89088 6177. E-mail: hyongdoo.jang@curtin.edu.au

${ }^{1}$ Corresponding author. Email: hyongdoo.jang@curtin.edu.au 


\title{
Support characteristics of eco-spiral pile with respect to twisting angle and ratio of borehole diameter to pile width
}

\begin{abstract}
This study numerically analysed the characteristics of eco-spiral piles (Eco-SPs) as multi-purpose geotechnical supports. The behaviour of eco-spiral piles in the ground was studied with respect to their twisting angle and the ratio of borehole diameter to eco-spiral pile width using FLAC-3D based on the finite-difference method. A cement mortar grout was modelled to sustain the eco-spiral pile in a sandy soil. Relationships were found among the eco-spiral pile's twisting angle, pull-out load, and maximum shear stress. The results should aid the further design of the bolts for application in a range of circumstances.
\end{abstract}

Keywords: eco-spiral pile; FLAC-3D; twisting angle; pull-out load; maximum shear stress.

\section{Introduction}

Supports such as rock bolts, cable bolts, and ground anchors are long established as temporary or permanent support systems in both mining and civil engineering. They have been widely used to improve soil and rock properties from within the ground. These supports all comprise four principal components: the rock, the element, the internal fixture, and the external fixture [1]. Interactions among these components define the mechanical and frictional behaviour of supports. Accordingly, the components determine the mechanics of reinforcement behaviour and the proper installation of reinforcement; they also influence laboratory tests results and in situ mechanical properties. Winsor and Thompson [2] classified three fundamental types of reinforcement system considering the load transfer concept: continuously mechanically coupled (CMC), continuously frictionally coupled (CFC), and discretely mechanically or frictionally coupled (DMFC). Rock bolts that fully grouted with cement and resin would classified as CMC systems while split-set and Swellex bolts are typical CFC systems. Bolts anchored by a slit and wedge mechanism or an expansion shell are DMFC systems.

Many scholars have been working on rock bolts through laboratory and in situ tests as well as conducting numerical analyses. [3-8]. Yazici and Kaiser [3] developed a bond strength model (BSM) considering axial and lateral displacements, confining pressure, and the bond strength. They concluded that the ultimate load increases with increasing rock-to-grout stiffness ratio, strength of the grout, and friction coefficient between the bolt and the grout. It also found that the ultimate load decreases with increasing diameter of the borehole. Kaiser et al. [4] studied the effect of changing stress on the bond strength of fully grouted cable bolts. Based on 
the BSM, their work found that mining-induced stress change is one of the most important parameters to control the bond strength, which is mainly frictional and depends on the pressure at the cable-grout interface. According to Hyett et al. [5-6], the capacity of cable bolt critically depends on grout properties, embedment lengths, radial splitting of the concrete cover surrounding the cable, and shearing of the cable against the concrete during pull-out testing. Hyett et al. [7] also presented analytical solutions for the distribution of displacement and load along fully grouted cable bolts during excavation in either continuous or discontinuous distributions of rock. They showed that fully grouted reinforcement is more effective in hard rock than in soft rock. Obara et al. [8] suggested a constitutive law using the shear resistance model to study the bond failure model between cable bolt and grout. They confirmed that the resistance shear stress depends mainly on the Young's modulus of the surrounding rock mass.

Numerous researchers have performed additional studies on rock bolts [9-22]. Farmer [9] compared the theoretical shear stress distribution along a loaded resin grouted rock anchor with experimental shear stress distributions obtained from tests on instrumented anchors in concrete, limestone, and chalk. The experimental shear stress distribution was similar to the theoretical distribution at low anchor loads in concrete, but there was significant debonding in limestone and chalk. Sharma and Pande [10] presented the behaviour of jointed rock masses reinforced by passive, fully grouted rock bolts. They showed that the dilatancy of the rock joints and the orientation of the bolts are the most important factors determining the effectiveness of the bolts. Stille et al. [11] represented a closed form, elastoplastic analytic solution for grouted bolts considering four different approaches to bolt performance. The bolt load distribution obtained from the analytic solutions agreed well with the measured results. Aydan [12] investigated the anchorage mechanism of grouted rock bolts and the effect of various parameters such as the ratio of the bolt to borehole diameter and the behaviour of the bolt-grout interface under triaxial stress in a series of push and pull-out tests. He reported that the loadbearing capacity of a bolt is $25 \%$ higher during pushing than pulling out. In addition, the study classified the observed failure modes into three types: failure along the bolt-grout interface, failure along the grout-rock interface, and failure by splitting of grout and rock annulus. Indraratna and Kaiser [13] introduced a design approach for the application of fully grouted bolts as a passive support system in underground openings, stating that the product of the borehole diameter and the bond strength of the grout-rock interface are greater than that of the bolt diameter and the bond strength of the bolt-grout interface. Li and Stillborg [14] developed three analytical models for predicting the behaviour of fully coupled rock bolts subjected to a concentrated pull-out load, the opening of individual rock joints, and bolts installed in uniformly deformed rock masses. Fahimifar and Soroush [15] modelled the interaction between rock mass and grouted rock bolts by using theoretical ground reaction curves and by extending two models of rock behaviour: brittle and strain softening behaviours, and non-linear peak strength criterion. 
A parametric study by Goel et al. [16] explored the influence of five shapes of underground opening on the maximum induced boundary stress using the numerical analysis code FLAD-3D, which was developed for estimating the roof and wall bolt length for these shapes of underground openings. They concluded that the optimal bolt length varies with the shape of the underground opening, in situ stress, and rock mass type. Xiao and Chen [17] analysed the load transfer mechanism of a tension-type anchor and the mechanical characteristics of the anchorage segment based on the shear displacement method. The shear stress first increased, then decreased, and finally tended toward the residual strength with increasing distance from the bottom of the anchorage body. The displacement increased with increasing distance from the bottom of the anchorage body and the anchorage bearing capacity increased with increasing anchorage radius. Ren et al. [18] presented an analytical solution for predicting the full range mechanical behaviour of grouted rock bolts in tension based on a realistic tri-linear bond-slip model with residual bond strength at the grout-bolt interface. They divided the full range of behaviours into five consecutive stages and obtained the ultimate load and the effective anchor length. Martín et al. [19] proposed a new analytical approach to predicting the mechanical behaviour of fully grouted rock bolts subjected to pull-out testing. They confirmed that the theoretical approach can provide a complete solution to predict and understand the behaviour of bolts under tensile loads. Bobet and Einstein [20] presented analytical solutions for stresses and displacements of the rock and reinforcement around a tunnel. Their use of a finite-element method provided reasonable results. Cao et al. [21] reviewed and discussed the failure modes of rock and cable bolts. According to their study, the shear slip and shear stress at the grout-bolt interface, the load-displacement relationships, and the axial stress in the bolt can be derived for each of the five distinct loading stages i.e., elastic, elastic-softening, elastic-softeningdebonding, softening-debonding, and debonding. He et al. [22] analytically investigated the performance of fully grouted rock bolts in several typical scenarios including pull-out tests, suspending loosened blocks, and incrementing a joint aperture.

Hirata et al. [23] introduced the spiral bolts. This bolts were developed as new reinforcements for ground foundations, which can be installed in soft ground and rock mass relatively easily compared with conventional rock bolts or cable bolts [24]. Few experimental studies have done on the spiral bolts [23-25]. In recent, Sato et al. [26] reported an effect of shaft rotation of driven spiral piles on vertical bearing capacity. They confirmed that the shaft rotary condition has a significant impact on the penetration resistance and vertical bearing capacity of the spiral pile. The aim of this study is to numerically analyse the support characteristics of the eco-spiral piles (Eco-SPs) as eco-friendly, multi-purpose, geotechnical support materials. For this purpose, we first analysed changes in the ground behaviour according to the twisting angle of the eco-spiral pile using FLAC-3D based on a finitedifference method. Secondly, we analysed changes in ground motion with respect to borehole 
diameter and the width ratio of the eco-spiral pile. The final part of this work summarises the results and examines the support characteristics of eco-spiral piles according to the twisting angle.

\section{Experiments}

Input data for the eco-spiral pile and grout required for the numerical analysis have been obtained through various laboratory tests. As shown in Figure 1, the eco-spiral pile is a spiralshaped support made by applying axial rotation to pile ends of a steel sheet bar [24]. Pull-out testing employed an eco-spiral pile of SD350 material of which $9 \mathrm{~mm}$ thick, $75 \mathrm{~mm}$ wide, and $540 \mathrm{~mm}$ long. Cement mortar was selected as the grout material to fill the borehole in a sandy soil. The composition of the injection material is a major factor affecting the adhesion of the support. Hyett et al. [5] reported that the support capacity is optimised when water and cement are mixed in a ratio of less than 0.4. This study assessed the grout using cylindrical specimens (diameter, $50 \mathrm{~mm}$; height, $100 \mathrm{~mm}$ ) comprising Portland cement, standard sand, and water mixed at a constant weight ratio (1:2:1); specimens were cured for 28 days.

The Young's modulus and Poisson's ratio of the eco-spiral pile and grout were determined by uniaxial compression tests as shown in Figure 2 . The density of the grout was measured as demonstrated in Figure 3. The adhesive strength and internal friction angle were obtained from Brazilian tensile tests and triaxial compression tests. The confining pressure in the latter test was set to 1,2 , and $3 \mathrm{MPa}$. The above tests were conducted based on guidance from the ISRM [27]. Figure 4 depicts the uniaxial compression test that results strength, Young's modulus, and Poisson's ratio of the eco-spiral pile as $122 \mathrm{MPa}, 64 \mathrm{GPa}$, and 0.28 respectively. Uniaxial and triaxial compression tests and Brazilian test were conducted to acquire the properties of the grout as demonstrated in Figure 5. The density of the grout revealed as $1695.8 \mathrm{~kg} / \mathrm{m}^{3}$ where the uniaxial compressive strength is $7 \mathrm{MPa}$, Young's modulus is $4.4 \mathrm{GPa}$, Poisson's ratio is 0.20 , adhesive strength is $1.1 \mathrm{MPa}$, and the internal friction angle analysed is $45.8^{\circ}$.

\section{Numerical analysis}

FLAC-3D numerical analysis code, a three-dimensional ground-analysis program based on the finite-difference method, developed by ITASCA has been used for examining the support characteristics of the eco-spiral pile [28]. Elastic model analysis for the eco-spiral pile requires input data, such as density, Young's modulus, and Poisson's ratio. Elasto-plastic model analysis for the ground (here grout and sandy soil) needs input data including cohesion, internal friction angle, and tensile strength as well as density, Young's modulus, and Poisson's ratio. Input data 
of the eco-spiral pile and grout were obtained from laboratory tests, and those of the sandy soil were taken from Korean average data.

Figure 6 shows the geometry of the numerical model to be based on a cylindrical ground volume of diameter $200 \mathrm{~cm}$ and depth $200 \mathrm{~cm}$. After drilling a $10 \mathrm{~cm}$ wide borehole in the center of the ground, the grout was injected, and then an eco-spiral pile was installed. The bolt was modelled to be $1 \mathrm{~cm}$ thick, $10 \mathrm{~cm}$ wide, and $100 \mathrm{~cm}$ long. The whole mesh number of elements and nodes varied depending on the twisting angles and the ratios of borehole diameter and eco-spiral pile width represents in Table 1. Displacement was constrained to the X-, Y-, and $\mathrm{Z}$-axis directions at the boundary condition. The pull-out load was applied nonlinearly through the speed reduction factor (Figure 7). The analysis was divided into 10 steps per 1000 steps for a total of 10,000. The ground condition was examined according to the depth and distance from the center of the ground. Five twisting angles $(\alpha)$ were selected for the eco-spiral piles: $0^{\circ}, 15^{\circ}, 30^{\circ}, 45^{\circ}$, and $60^{\circ}$, and the ground behaviour was analysed in each case. In addition, the ratio of the diameter of the borehole $\left(\mathrm{D}_{\mathrm{BH}}\right)$ to the width of an eco-spiral pile $\left(\mathrm{W}_{\mathrm{Eco}}\right.$ $\mathrm{SP})$ with $\alpha=45^{\circ}$ was tested; the ground behaviour was analysed at four different ratios $(1.0,1.5$, 2.0, and 3.0). Table 2 summarises the input data for numerical analysis.

\section{Ground behaviour with respect to twisting angle}

The ground behaviour at twisting angles of $\alpha=0^{\circ}, 15^{\circ}, 30^{\circ}, 45^{\circ}$, and $60^{\circ}$ was analysed. Figure 8 shows the $\mathrm{X}-\mathrm{Y}$ and $\mathrm{X}-\mathrm{Z}$ sections of the model and the shapes of the variously twisted piles. At $\alpha=15^{\circ}$ three pitches are formed, each $37 \mathrm{~cm}$ apart. Doubling $\alpha$ to $30^{\circ}$ gives six pitches at $17 \mathrm{~cm}$ intervals. Twisting to $\alpha=45^{\circ}$ gives 10 pitches spaced $10 \mathrm{~cm}$ apart. Finally, 17 pitches at $6 \mathrm{~cm}$ spacings emerge at $\alpha=60^{\circ}$. Characteristics of the ground model and the eco-spiral pile with respect to $\alpha$ are summarised in Table 3 .

Table 4 lists numerical results of pull-out testing with respect to $\alpha$. The pull-out load for $8 \mathrm{~mm}$ displacement was lowest at $\alpha=15^{\circ}$ and greatest at $\alpha=60^{\circ}$; all three other twisting angles give similar intermediate values as shown in Figure 9. The magnitude of the maximum pull-out load according to the twisting angle was $\alpha=15^{\circ}\left(\mathrm{P}_{\max }=22.1 \mathrm{kN}\right)<\alpha=0^{\circ}\left(\mathrm{P}_{\max }=63.4 \mathrm{kN}\right)<\alpha$ $=30^{\circ}\left(\mathrm{P}_{\max }=64.4 \mathrm{kN}\right)<\alpha=45^{\circ}\left(\mathrm{P}_{\max }=76.4 \mathrm{kN}\right)<\alpha=60^{\circ}\left(\mathrm{P}_{\max }=136.6 \mathrm{kN}\right)$. Figure 10 shows the change in displacement with distance from the borehole center by dividing the total numerical analysis 10,000 steps by 1000 steps. In steps $0-1000$, the displacement occurred only in the vicinity of the borehole but not elsewhere. In steps 1001-2000, the displacement range tended to decrease from the borehole center as $\alpha$ increased from $0^{\circ}$ to $60^{\circ}$. In steps $2001-$ 10,000, the displacement occurred mostly near the borehole, and it tended to decrease nonlinearly with increasing distance from the borehole center. The distribution of the pull-out load in the $\mathrm{X}-\mathrm{Z}$ section for each step with respect to $\alpha$ is shown in Figure 11. In all cases, as the 
pull-out load increased, the entire ground displaced, but the lower part moved more than the upper.

Figure 12 shows the maximum shear stress and its distribution in the $\mathrm{X}-\mathrm{Z}$ section for eco-spiral piles with different twisting angles during pull-out testing. The maximum shear stress was greatest at $\alpha=30^{\circ}$ and least at $\alpha=0^{\circ}$. The maximum shear stress increased sharply as $\alpha$ initially increased to $30^{\circ}$, then gradually decreased or remained nearly constant as $\alpha$ further increased to $60^{\circ}$. The magnitude of the maximum shear stress according to the twisting angle of eco-spiral pile was $\alpha=0^{\circ}\left(S_{\max }=13.4 \mathrm{kPa}\right)<\alpha=15^{\circ}\left(S_{\max }=150.4 \mathrm{kPa}\right)<\alpha=30^{\circ}\left(\mathrm{S}_{\max }=\right.$ $511.6 \mathrm{kPa})<\alpha=45^{\circ}\left(\mathrm{S}_{\max }=441.8 \mathrm{kPa}\right)<\alpha=60^{\circ}\left(\mathrm{S}_{\max }=425.8 \mathrm{kPa}\right)$. The observed distribution of the maximum shear stress shows that it acted on the eco-spiral pile in the early stages of pulling out, and then extended to the surroundings of the eco spiral pile as the pull-out load increased.

Figure 13 shows the maximum shear stress and its distribution on the $\mathrm{X}-\mathrm{Y}$ section at various steps at a depth of $70 \mathrm{~cm}$, which is the depth that the in-ground displacement and shear stress are most affected by the twisting angle of the eco-spiral pile. The figure shows similar trends to Figure 12. The magnitude of the maximum shear stress at a depth of $70 \mathrm{~cm}$ with respect to $\alpha$ was $\alpha=0^{\circ}\left(S_{\max / 70}=64.4 \mathrm{kPa}\right)<\alpha=15^{\circ}\left(\mathrm{S}_{\max / 70}=135.3 \mathrm{kPa}\right)<\alpha=30^{\circ}\left(\mathrm{S}_{\max / 70}=\right.$ $511.5 \mathrm{kPa})<\alpha=45^{\circ}\left(\mathrm{S}_{\max / 70}=434.6 \mathrm{kPa}\right)<\alpha=60^{\circ}\left(\mathrm{S}_{\max / 70}=411.7 \mathrm{kPa}\right)$. Here, the maximum shear stress at the center of the eco-spiral pile was small at the beginning of pulling out, and then became concentrated at the boundary between the eco-spiral pile and the grout as the pullout load increased. The shear fracture zone appeared to enlarge gradually as the pull-out load increased, before finally forming in the entire grout.

\section{Ground behaviour with respect to borehole-to-pile width}

The bond strength of the support depends on factors such as the nature of the cement, its mixing ratio with water, the fixing length of the support, and the constraint pressure around the grout [5]. This study analysed the ground behaviour when a $10 \mathrm{~cm}$ wide eco-spiral pile with a twisting angle of $45^{\circ}$ was placed in the ground in boreholes of diameter $10,15,20,30 \mathrm{~cm}$ (i.e., $\left.\mathrm{D}_{\mathrm{BH}} / \mathrm{W}_{\mathrm{Eco-SP}}=1.0,1.5,2.0,3.0\right)$. Figure 14 shows the $\mathrm{X}-\mathrm{Y}$ section and the models used for the different $\mathrm{D}_{\mathrm{BH}} / \mathrm{W}_{\mathrm{Eco-SP}}$ ratios.

Table 5 summarises the results of pull-out tests with the different $\mathrm{D}_{\mathrm{BH}} / \mathrm{W}_{\mathrm{Eco-SP}}$ ratios. The relationships between pull-out load and displacement in Figure 15 show maximum pull-out loads of $76.4 \mathrm{kN}$ for $\mathrm{D}_{\mathrm{BH}} / \mathrm{W}_{\mathrm{Eco-SP}}=1.0,185.6 \mathrm{kN}$ for $\mathrm{D}_{\mathrm{BH}} / \mathrm{W}_{\mathrm{Eco-SP}}=1.5,430.3 \mathrm{kN}$ for $\mathrm{D}_{\mathrm{BH}} / \mathrm{W}_{\text {Eco- }}$ $\mathrm{SP}=2.0$, and $743.7 \mathrm{kN}$ for $\mathrm{D}_{\mathrm{BH}} / \mathrm{W}_{\mathrm{Eco-SP}}=3.0$. The maximum pull-out load tended to increase with increasing $\mathrm{D}_{\mathrm{BH}} / \mathrm{W}_{\mathrm{Eco}-\mathrm{SP}}$ : at $\mathrm{D}_{\mathrm{BH}} / \mathrm{W}_{\mathrm{Eco}-\mathrm{SP}}=3.0$ it was about 9.6 times larger than that $\mathrm{D}_{\mathrm{BH}} / \mathrm{W}_{\mathrm{Eco-SP}}=1.0$. Figure 16 presents the change in displacement with distance from the borehole center by dividing the total numerical analysis steps $(10,000)$ into 1000 -step sections. 
In steps $0-1000$, the behaviour was almost similar to the change of displacement according to the twisting angle of the eco-spiral pile. However, in steps 1001-2000, the displacement at all $\mathrm{D}_{\mathrm{BH}} / \mathrm{W}_{\mathrm{Eco-SP}}$ ratios was generally $0.2-0.3 \mathrm{~m}$ from the borehole center, and only rarely more. In steps $2001-10,000$, the displacement at $\mathrm{D}_{\mathrm{BH}} / \mathrm{W}_{\mathrm{Eco-SP}}=1.0$ and 1.5 increased greatly to $0.5-$ $0.6 \mathrm{~m}$, and then remained nearly constant. On the other hand, the displacement at $\mathrm{D}_{\mathrm{BH}} / \mathrm{W}_{\mathrm{Eco}}$ $\mathrm{SP}=2.0$ and 3.0 showed the same trend as during steps 1001-2000. Distributions of pull-out load at selected steps for the different $\mathrm{D}_{\mathrm{BH}} / \mathrm{W}_{\mathrm{Eco}-\mathrm{SP}}$ ratios on the $\mathrm{X}-\mathrm{Z}$ section are shown in Figure 17. The results agreed well with those for the twisting angle demonstrated in Figure 11.

Figure 18 shows the maximum shear stress and its distribution on the $\mathrm{X}-\mathrm{Z}$ section for the different $\mathrm{D}_{\mathrm{BH}} / \mathrm{W}_{\mathrm{Eco}-\mathrm{SP}}$ ratios due to the pull-out load. The maximum shear stress was $441.8 \mathrm{kPa}$ at $\mathrm{D}_{\mathrm{BH}} / \mathrm{W}_{\mathrm{Eco-SP}}=1.0,953.7 \mathrm{kPa}$ at $\mathrm{D}_{\mathrm{BH}} / \mathrm{W}_{\mathrm{Eco-SP}}=1.5,3016.8 \mathrm{kPa}$ at $\mathrm{D}_{\mathrm{BH}} / \mathrm{W}_{\mathrm{Eco-SP}}=2.0$, and $6667.3 \mathrm{kN}$ at $\mathrm{D}_{\mathrm{BH}} / \mathrm{W}_{\mathrm{Eco-SP}}=3.0$. The maximum shear stress tended to increase as the $\mathrm{D}_{\mathrm{BH}} / \mathrm{W}_{\mathrm{Eco-SP}}$ ratio increased. At $\mathrm{D}_{\mathrm{BH}} / \mathrm{W}_{\mathrm{Eco-SP}}=3.0$ it was about 15.1 times larger than that $\mathrm{D}_{\mathrm{BH}} / \mathrm{W}_{\mathrm{Eco-SP}}=1.0$. The maximum shear stress increased rapidly above a ratio of $\mathrm{D}_{\mathrm{BH}} / \mathrm{W}_{\mathrm{Eco}-}$ $\mathrm{SP}=1.5$. The distribution shows that the maximum shear stress acted on the eco-spiral pile in the early stage of the pull-out load, and then extended to the surroundings of the eco-spiral pile as the load increased.

In addition, Figure 19 represents the maximum shear stress at a depth of $70 \mathrm{~cm}$ and its distribution on the $\mathrm{X}-\mathrm{Y}$ section at selected steps. The chosen depth is that at which the inground displacement and shear stress are most affected by the ratio of $\mathrm{D}_{\mathrm{BH}} / \mathrm{W}_{\mathrm{Eco-SP}}$ due to the pull-out load. The observed trends agreed very well with Figure 18. The magnitude of the maximum shear stress was $434.6 \mathrm{kPa}$ at $\mathrm{D}_{\mathrm{BH}} / \mathrm{W}_{\mathrm{Eco-SP}}=1.0,1052.4 \mathrm{kPa}$ at $\mathrm{D}_{\mathrm{BH}} / \mathrm{W}_{\mathrm{Eco-SP}}=1.5$, $2652.4 \mathrm{kPa}$ at $\mathrm{D}_{\mathrm{BH}} / \mathrm{W}_{\mathrm{Eco}-\mathrm{SP}}=2.0$, and $4589.4 \mathrm{kN}$ at $\mathrm{D}_{\mathrm{BH}} / \mathrm{W}_{\mathrm{Eco-SP}}=3.0$. The maximum shear stress tended to increase as the $\mathrm{D}_{\mathrm{BH}} / \mathrm{W}_{\mathrm{Eco}-\mathrm{SP}}$ ratio increased. The maximum shear stress at $\mathrm{D}_{\mathrm{BH}} / \mathrm{W}_{\mathrm{Eco}-}$ $\mathrm{SP}=3.0$ was about 10.6 times larger than that at $\mathrm{D}_{\mathrm{BH}} / \mathrm{W}_{\mathrm{Eco}-\mathrm{SP}}=1.0$. The distributions of the maximum shear stress on the $\mathrm{X}-\mathrm{Y}$ section at various steps show it to be concentrated in the clockwise direction at the ends of the eco-spiral pile in the early stages of the pull-out load; it then extended to the entire grout as the pull-out load gradually increased.

\section{Conclusions}

To evaluate the support characteristics of the eco-spiral pile (Eco-SP), variations of the ground behaviour according to the twisting angle and the ratio of borehole diameter and width of the eco-spiral pile were analysed by numerically modelling pull-out tests using FLAC-3D. The results are as follows.

The twisting angle of the eco-spiral pile resulted in the following magnitudes of maximum pull-out load: $\alpha=15^{\circ}\left(\mathrm{P}_{\max }=22.1 \mathrm{kN}\right)<\alpha=0^{\circ}\left(\mathrm{P}_{\max }=63.4 \mathrm{kN}\right)<\alpha=30^{\circ}\left(\mathrm{P}_{\max }=\right.$ $64.4 \mathrm{kN})<\alpha=45^{\circ}\left(\mathrm{P}_{\max }=76.4 \mathrm{kN}\right)<\alpha=60^{\circ}\left(\mathrm{P}_{\max }=136.6 \mathrm{kN}\right)$. It led to the following 
magnitudes of the maximum shear stress: $\alpha=0^{\circ}\left(S_{\max }=13.4 \mathrm{kPa}\right)<\alpha=15^{\circ}\left(\mathrm{S}_{\max }=150.4 \mathrm{kPa}\right)$ $<\alpha=30^{\circ}\left(\mathrm{S}_{\max }=511.6 \mathrm{kPa}\right)<\alpha=45^{\circ}\left(\mathrm{S}_{\max }=441.8 \mathrm{kPa}\right)<\alpha=60^{\circ}\left(\mathrm{S}_{\max }=425.8 \mathrm{kPa}\right)$. The pull-out load was least at a twisting angle of $15^{\circ}$ and greatest at $60^{\circ}$; all three other angles led to similar intermediate load values. The maximum shear stress was greatest at a twisting angle of $30^{\circ}$ and least at $0^{\circ}$. It increased sharply as the twisting angle rose to $30^{\circ}$, and then gradually decreased or remained nearly constant as the angle increased further to $60^{\circ}$.

Finally, the ratio of the borehole diameter and eco-spiral pile width led to maximum pull-out loads of $76.4 \mathrm{kN}$ for $\mathrm{D}_{\mathrm{BH}} / \mathrm{W}_{\mathrm{Eco}-\mathrm{SP}}=1.0,185.6 \mathrm{kN}$ for $\mathrm{D}_{\mathrm{BH}} / \mathrm{W}_{\mathrm{Eco-SP}}=1.5,430.3 \mathrm{kN}$ for $\mathrm{D}_{\mathrm{BH}} / \mathrm{W}_{\mathrm{Eco-SP}}=2.0$, and $743.7 \mathrm{kN}$ for $\mathrm{D}_{\mathrm{BH}} / \mathrm{W}_{\mathrm{Eco-SP}}=3.0$. The maximum shear stress was $441.8 \mathrm{kPa}$ at $\mathrm{D}_{\mathrm{BH}} / \mathrm{W}_{\mathrm{Eco-SP}}=1.0,953.7 \mathrm{kPa}$ at $\mathrm{D}_{\mathrm{BH}} / \mathrm{W}_{\mathrm{Eco-SP}}=1.5,3016.8 \mathrm{kPa}$ at $\mathrm{D}_{\mathrm{BH}} / \mathrm{W}_{\mathrm{Eco-SP}}=2.0$, and $6667.3 \mathrm{kN}$ at $\mathrm{D}_{\mathrm{BH}} / \mathrm{W}_{\mathrm{Eco-SP}}=3.0$. The maximum pull-out load tended to increase as the $\mathrm{D}_{\mathrm{BH}} / \mathrm{W}_{\mathrm{Eco-SP}}$ increased. The maximum shear stress acted on the eco-spiral pile in the early stages of the pull-out load, and then extended to the eco-spiral pile's surroundings as the pull-out load increased.

\section{References}

[1] C.R. Winsdor, Rock reinforcement systems, Int. J. Rock Mech. Min. Sci. \& Geomech. Abstr. 34 (1997), pp. 919-951.

[2] C.F. Windsor, and A.G. Thompson, Rock reinforcement-technology, testing, design and evaluation, Comprehensive Rock Engineering Principles, Practice and Projects, Ed. J.A. Hudson, V. 41993, 1993, pp. 451-84.

[3] S. Yazici, and P.K. Kaiser, Bond strength of grouted cable bolts, Int. J. Rock Mech. Min. Sci. \& Geomech. Abstr, 29 (1992), pp. 279-292.

[4] P.K. Kaiser, S. Yazici, and J. Nose, Effect of stress change on the bond strength of fully grouted cables, Int. J. of Rock Mech. Min. Sci. \& Geomech. Abstrs, 29 (1992), pp. 293306.

[5] A.J. Hyett, W.F. Bawden, and R.D. Reichert, The effect of rock mass confinement on the bond strength of fully grouted cable bolts, Int. J. Rock Mech. Min. Sci. \& Geomech. Abstr. 29 (1992), pp. 503-524.

[6] A.J. Hyett, W.F. Bawden, G.R. Macsporran, and M. Moosavi, A constitutive law for bond failure of fully-grouted cable bolts using a modified Hoek cell, Int. J. Rock Mech. Min. Sci. \& Geomech. Abstrs. 32 (1995), pp. 11-36. 
[7] A.J. Hyett, M. Mossavi, and W. Bawden, Load distribution along fully grouted bolts, with emphasis on cable bolt reinforcement, Int. J. Numerical \& Analytical Methods in Geomechanics, 20 (1996), pp. 517-544.

[8] Y. Obara, Y, Maeno, and S.S. Kang, Constitutive law of fully-grouted cable bolts and its application to support design, J. Mining and Materials Processing Institute of Japan (MMIJ) 126 ( 2010), pp. 432-439. (in Japanese with an English abstract)

[9] I.W. Farmer, Stress distribution along a resin grouted rock anchor, Int. J. Rock Mech. Min. Sci. \& Geomech. Abstr. 12 (1975), pp. 347-351.

[10] K.G. Sharma, and G.N. Pande, Stability of rock masses reinforced by passive, fully grouted rock bolts, Int. J. Rock Mech. Min. Sci. \& Geomech. Abstr. 25 (1988), pp. 273-285.

[11] H. Stille, M. Holmberge, and G. Nord, Support of weak rock with grouted bolts and shotcrete, Int. J. Rock Mech. Min. Sci. \& Geomech. Abstrs. 26 (1989), pp. 99-113.

[12] O. Aydan, The stabilisation of rock engineering structures by rock bolts, Geotechnical Engineering, Ph.D. Thesis, Nagoya, Nagoya University, 1989.

[13] B. Indraratna, and P.K. Kaiser, Analytical model for the design of grouted rock bolts, Int. J. of Numerical \& Analytical Methods in Geomechanics, 14 (1990), pp. 227-251.

[14] C. Li, and B. Stillborg, Analytical models for rock bolts. Int. J. Rock Mech. Min. Sci. \& Geomech. Abstrs, 36 (1999), pp. 1013-1029.

[15] A. Fahimifar, and $\mathrm{H}$ Soroush, A theoretical approach for analysis of the interaction between grouted rockbolts and rock masses, Tunnelling and Underground Space Technology 20 (2005), pp. 333-343.

[16] R.K. Goel, A. Swarup, and R.R. Sheorey, Bolt length requirement in underground openings, Int. J. Rock Mech. \& Min. Sci. 44 (2007), pp. 802-811.

[17] S.J. Xiao, and C.F. Chen, Mechanical mechanism analysis of tension type anchor based on shear displacement method, J. Central South Univ. Tech.15 (2008), pp. 106--110.

[18] F.F. Ren, Z.J. Yang, J.F. Chen, and W.W. Chen, An analytical analysis of the full-range behaviour of grouted rockbolts based on a tri-linear bond-slip model, Construction and Building Materials 24 (2010), pp. 361-370.

[19] L.B. Martín, M. Tijani, and F. Hadj-Hassen, A new analytical solution to the mechanical behaviour of fully grouted rockbolts subjected to pull-out tests, Construction and Building Materials 25 (2011), pp. 749-755. 
[20] A. Bobet, and H.H Einstein, Tunnel reinforcement with rockbolts, Tunneling and Underground Space Technology 26 (2011), pp. 100-123.

[21] C. Cao, J. Nemcik, R. Ting, and N. Azis, A study of rock bolting failure modes, Int. J. Min. Sci. \& Tech. 23 (2013), pp. 79-88.

[22] L. He, X.M. An, and Z.Y. Zhao, Fully grouted rock bolts: An analytical investigation, Rock Mech. Rock Eng. 48 (2015), pp. 1181-1196.

[23] A. Hirata, S. Kokaji, S, Fujita, A. Akamine, M. Fujita, and T. Goto, Dilation stress in borehole induced by a spiral anchor, Proceedings of the 3rd International Symposium of Rock Stress, 2003, pp. 499-505.

[24] S.S. Kang, A. Hirata, and Y. Obara, A method for estimating of axial resistance of spiral bar developed as a new earth support system, J. the Korean Society of Civil Engineers 25 (2005), pp. 387-394. (in Korean with an English abstract)

[25] A. Hirata, S. Kokaji, S.S., Kang, and G. Goto, Study on the estimation of the axial resistance of spiral bar based on interaction with ground, J. Mining and Materials Processing Institute of Japan (MMIJ) 121 (2005), pp. 370-377. (in Japanese with an English abstract)

[26] T. Sato, J. Otani, B. Chevalier, and T. Eskisar, Effect of shaft rotation of driven piles on vertical bearing capacity, The Japanese Geotechnical Society, Special Issue 2 (2015), pp. 1304-1309.

[27] ISRM, Rock characterization testing and monitering, ISRM suggested methods, Ed. E.T. Brown, The Commission on Testing Methods, International Society for Rock Mechanics, Pergamon Press, 1981, pp. 1-211.

[28] ITASCA, Theory and background for FLAC3D, Version 4.0, Itasca Consulting Group Inc., Minnesota, 2009, pp. 1-32. 